\title{
Expression, characterization, and antimicrobial ability of T4 lysozyme from methylotrophic yeast Hansenula polymorpha A16
}

\author{
WANG Nan ${ }^{1}$, WANG YueJu ${ }^{2}$, LI GangQiang ${ }^{1}$, SUN Ning $^{1} \&$ LIU DeHu ${ }^{1 *}$ \\ ${ }^{1}$ Biotechnology Research Institute, Chinese Academy of Agricultural Sciences, Beijing 100081, China; \\ ${ }^{2}$ Department of Natural Sciences, Northeastern State University, Broken Arrow, Oklahoma 74014, USA
}

Received July 15, 2010; accepted March 31, 2011

\begin{abstract}
Lysozyme is an enzyme that is essential for protection against bacterial infections. In this study, a T4 lysozyme gene was cloned into the yeast expression vector pPIC9K under the control of the Pichia pastoris glyceraldehyde-3-phosphate dehydrogenase promoter (pGAP). A Hansenula polymorpha-derived ribosomal DNA (rDNA)-targeting element was inserted into the expression vector and was critical for stable DNA integration into the $H$. polymorpha chromosome. Recombinant T4 lysozyme was successfully expressed in the yeast $H$. polymorpha A16; $0.49 \mathrm{~g} \mathrm{~L}^{-1}$ secreted recombinant $\mathrm{T} 4$ lysozyme was obtained $72 \mathrm{~h}$ after incubation in culture broth that had an initial $\mathrm{pH}$ of 6.0. Recombinant T4 lysozyme showed lytic activity against the cell walls of the gram positive bacteria, Micrococcus lysodeikticus, and the gram negative bacteria Xanthomonas campestris pv. malvacearum and Xanthomonas oryzae pv. oryzae. The zone of inhibition assay was used to evaluate antimicrobial activity. Mass spectrometry showed the N-terminal sequence of recombinant T4 lysozyme was identical to that of the native enzyme. SDS-PAGE indicated that the molecular mass of recombinant T4 lysozyme was $18.7 \mathrm{kD}$ which corresponds to a monomer of the native enzyme. SDS-PAGE without $0.2 \mathrm{~mol} \mathrm{~L}^{-1}$ dithiothreitol treatment detected two bands $(15$ and $31 \mathrm{kD})$ suggesting that some recombinant T4 lysozyme formed inter- and intra-molecular disulfide bonds which resulted in loss of enzyme activity.
\end{abstract}

T4 lysozyme, antimicrobial activity, Hansenula polymorpha, pGAP, rDNA

Citation: Wang N, Wang Y J, Li G Q, et al. Expression, characterization, and antimicrobial ability of T4 lysozyme from methylotrophic yeast Hansenula polymorpha A16. Sci China Life Sci, 2011, 54: 520-526, doi: 10.1007/s11427-011-4174-x

Lysozymes are enzymes that are naturally present in prokaryotes and eukaryotes, including bacteria [1], plants [2], and animals [3]. They possess antimicrobial activity, inhibit tumor growth and angiogenesis, and may have therapeutic value in antitumor drug development [4]. Furthermore, cloned human, bovine, microbial [5], and hen egg-white $[6,7]$ lysozymes have been effectively used for in situ bio-preservation of foodstuffs.

The phage T4 lysozyme gene (GenBank accession No. AF158101) has been cloned and expressed in Escherichia

*Corresponding author (email: liudehu2006@126.com) coli and its structure and function has been extensively studied [8]. The monomeric lysozyme protein is 164 amino acid residues in length and has a molecular weight of 18.7 $\mathrm{kD}$. The antibacterial activity of T4 lysozyme involves hydrolysis of the bacterial cell wall peptidoglycan murein, and disruption of the bacterial cell membrane [9]. Recent reports showed that T4 lysozyme also has antifungal activity [10].

The phage T4 lysozyme gene has been expressed in various systems [10,11]; however, process efficiency and net yield of active protein are low. Previous studies indicate that E. coli transformed with plasmid containing page T4 gene expresses active T4 lysozyme at levels up to $2 \%$ of the 
cellular protein after induction with isopropyl-beta-D-thiogalactoside [11]. These recoveries are not high enough for practical applications.

Hansenula polymorpha is a safe reliable expression system that has been successfully developed for commercial-scale recombinant protein production [12-14]. Several $H$. polymorpha-derived products, including Hepatitis B vaccines and insulin, have been approved, marketed, and used in many countries [15]. In this study, we chose the methylotrophic yeast $H$. polymorpha, as the host organism for recombinant T4 lysozyme expression. T4 lysozyme was inserted into the pPIC9K expression vector driven by the Pichia pastoris pGAP promoter (GenBank accession No. U62648.1). $H$. polymorpha derived-ribosomal DNA (rDNA) (GenBank accession No. AF467695) was cloned into the transformation vector to serve as a target sequence for homologous recombination [16]. Recombinant T4 lysozyme was secreted in large quantities $\left(0.49 \mathrm{~g} \mathrm{~L}^{-1}\right)$ and its antimicrobial activity was characterized.

\section{Materials and methods}

\subsection{Strains, vectors, and reagents}

Yeast $H$. polymorpha A16 was kindly provided by Dr. Li Ying, Professor of China Agriculture University (Beijing, China). Micrococcus lysodeikticus (M. lysodeikticus), Xanthomonas campestris pv. malvacearum (X. c. malvacearum), and Xanthomonas oryzae pv. oryzae (X. o. oryzae) were obtained from China General Microbiological Culture Collection Center (Beijing, China). The plasmid pT-T4 was constructed in our laboratory. DNA primers were synthesized by Shanghai Sangon Biological Engineering Technology \& Services Co., Ltd. (Shanghai, China). Plasmid pPIC9K was purchased from Invitrogen Corp. (Carlsbad, CA, USA). PCR kits, T4 DNA ligase, and all restriction enzymes were obtained from Clonetech (Mountain View, CA, USA). DNA labeling kits were purchased from Roche Applied Science (Indianapolis, IN, USA). All chemicals, unless otherwise stated, were obtained from Sinopharm Chemical Reagent Beijing Co., Ltd. (Beijing, China).

\subsection{Construction of expression plasmids}

Bacterial transformations were carried out using E. coli DH5 $\alpha$, and plasmid DNA was isolated and purified using DNA kits (BioTeKe Corporation, Beijing, China).

The $P$. pastoris pGAP promoter (485 bp) was PCR amplified from the genome with the following primers: F-G, 5'-TAGAGCTCTTTTTTGTAGAAATGTCTTGGTGT-3'; R-G, 5'-TAGGATCCTGTGTTTTGATAGTTGTTCAATTG-3' (Sac I and Bam H I sites are underlined), and inserted into the Sac I and BamH I sites of the P. pastoris vector pPIC9K to yield the intermediate vector p9K-G. The T4 lysozyme gene was isolated from plasmid pT-T4 with EcoR I and Not I and ligated into the EcoR I/Not I sites of p9K-G to generate the yeast expression plasmid p9K-G-T4. A $2.4 \mathrm{~kb}$ rDNA fragment was PCR amplified from the genome of $H$. polymorpha with the primers: F-rD, 5'-AAGCATGCTTGCCATAGGCTAGTAATCC-3'; R-rD, 5'-AACATATGGAGACAGGTTAGTTTTACCC-3' (Sph I and Nde I are underlined), and cloned into the Nde I and Sph I sites of p9KG-T4 to generate the yeast expression plasmid p9K-G-T4rD. All DNA segments were confirmed at each step and upon completion by restriction digestion and DNA sequencing.

\subsection{Transformation of $\boldsymbol{H}$. polymorpha and detection of transformant copy numbers}

H. polymorpha A16 transformation was performed according to the method described by Liu et al. [17]. Prior to transformation, p9K-G-T4 and p9K-G-T4-rD were linearized with Xba I and purified (DNA Purification Kit; BioTeKe). Electrocompetent $H$. polymorpha cells were transformed with the linearized plasmids by electroporation using a Micropulser (200 $\Omega, 25 \mu \mathrm{F}, 1.5 \mathrm{kV}$, BTX ECM630, USA), immediately suspended in $1 \mathrm{~mL}$ non-selective YPDS media $(1 \%$ yeast extract, $2 \%$ peptone, $2 \%$ dextrose, $1.0 \mathrm{~mol} \mathrm{~L}^{-1}$ sorbitol), and plated on selective media (YPDS+G418, $0.3 \mathrm{mg} \mathrm{mL}^{-1}$ ). Plates were incubated at $37^{\circ} \mathrm{C}$ for $2-4 \mathrm{~d}$.

Ten randomly picked transformants were screened by PCR using T4 lysozyme primers: F5, 5'-TAGAATTCATGAACATCTTCGAGAAGTTGAG-3'; R3, 5'-TGCGGCCGCTTACAAGTTCTTGTAAGCGTCCC-3'. To select multicopy integrants, 100 randomly picked transformants were plated on YPD media (1\% yeast extract, $2 \%$ peptone, $2 \%$ dextrose, $2 \%$ agar) containing increasing concentrations of $\mathrm{G} 418\left(0.5,1,2 \mathrm{mg} \mathrm{mL} \mathrm{m}^{-1}\right)$ at $37^{\circ} \mathrm{C}$. A randomly selected transformant designated H5 was further characterized by Southern blot analysis. $10 \mu \mathrm{g}$ H5 genome DNA was digested with $B g l$ II overnight and separated on a $0.8 \%$ agarose gel. The DNA was blotted onto an Amersham Hybond $^{\mathrm{TM}}$ membrane (GE Healthcare, USA) and probed with a digoxigenin labeled T4 lysozyme PCR fragment. Hybridization, washing, and chemiluminescent detection were performed with the DIG DNA Labeling Kit (Roche, USA).

\subsection{Determination of optimum $\mathrm{pH}$ and time of culture conditions}

Single H5 transformant colonies were picked from a YPD plate containing $2 \mathrm{mg} \mathrm{mL}^{-1} \mathrm{G} 418$, inoculated into $10 \mathrm{~mL}$ BMGY (1\% yeast extract, $2 \%$ peptone, $1.34 \%$ YNB, $4 \times 10^{-5} \%$ biotin, $1 \%$ glycerol medium; $\mathrm{pH}$ values: $5.8,6.0$, $6.2,6.4,6.6,7.0,7.2$, adjusted using $100 \mathrm{mmol} \mathrm{L}^{-1}$ potassium phosphate buffer) in $250 \mathrm{~mL}$ flasks, and cultured at $37^{\circ} \mathrm{C}$ with vigorous shaking (180-200 r min ${ }^{-1}$ ). Samples 
were taken at various time intervals $(24,48,72 \mathrm{~h})$ to investigate the effects of $\mathrm{pH}$ and incubation time on cell growth and recombinant T4 lysozyme expression. Cell densities were determined spectrophotometrically at an absorbance of $660 \mathrm{~nm}\left(A_{660}\right)$. The cells and culture supernatants were separated by centrifugation at $11000 \times g$ and $1^{\circ} \mathrm{C}$ for $1 \mathrm{~min}$. $10 \mu \mathrm{L}$ crude supernatant from each sample was treated with $0.2 \mathrm{~mol} \mathrm{~L}^{-1}$ dithiothreitol (DTT) and analyzed by sodium dodecyl sulfate-polyacrylamide gel electrophoresis (SDSPAGE) according to a previously described method using $15 \%$ (v/v) polyacrylamide gels. Protein was detected with Coomassie brilliant blue R-250 staining.

\subsection{Scale-up expression and purification of $\mathrm{T} 4 \mathrm{ly}$ - sozyme}

The selected $\mathrm{H} 5$ clone was inoculated in $5 \mathrm{~mL}$ BMGY medium at $37^{\circ} \mathrm{C}$ in a shaking $200 \mathrm{r} \mathrm{min}^{-1}$ incubator overnight and transferred into $500 \mathrm{~mL}$ BMGY at $37^{\circ} \mathrm{C}$ with vigorous shaking $\left(200 \mathrm{r} \mathrm{min}^{-1}\right)$ for $72 \mathrm{~h}$. The supernatant was collected by centrifugation at $4500 \times \mathrm{g}$ for $10 \mathrm{~min}$ and concentrated with $60 \%$ ammonium sulfate. The precipitate was collected by centrifugation at $12000 \times \mathrm{g}$ for $30 \mathrm{~min}$, re-suspended in $10 \mathrm{~mL} 50 \mathrm{mmol} \mathrm{L}^{-1}$ sodium phosphate buffer $\mathrm{pH} 7.2$, and dialyzed against $2 \mathrm{~L}$ of $50 \mathrm{mmol} \mathrm{L}{ }^{-1} \mathrm{pH} 7.2$ sodium phosphate buffer using a 12000-14000 MWCO membrane (GreenBird Co., Ltd., Shanghai, China) for $5 \mathrm{~h}$ at room temperature with three changes of dialysis buffer. After the last buffer change, protein dialysis was continued at $4^{\circ} \mathrm{C}$ overnight to ensure thorough exchange of buffering salts. Recombinant T4 lysozyme protein content was determined with a White/Ultraviolet transilluminator (UVP LLC, USA); $0.25 \mathrm{mg} \mathrm{mL}^{-1}$ hen egg-white lysozyme was used as the standard. $10 \mu \mathrm{L}$ of hen egg-white lysozyme and $10 \mu \mathrm{L}$ of crude supernatant were analyzed by SDS-PAGE and stained with Coomassie brilliant blue R-250 (Amersco, USA). Proteins on SDS-PAGE gels were analyzed with LabWork 3.0 software (UVP LLC). Recombinant T4 lysozyme protein content in the supernatant was estimated based on the hen egg-white lysozyme solution.

\subsection{Disulfide bonds and N-terminal sequence analysis}

To assess protein disulfide bond formation, $10 \mu \mathrm{L}$ lysozyme supernatant was treated with or without $0.2 \mathrm{~mol} \mathrm{~L}^{-1}$ DTT. The samples were boiled for $10 \mathrm{~min}$ and analyzed by SDSPAGE as previously described. To determine the $\mathrm{N}$-terminal amino acid sequence, purified recombinant T4 lysozyme was subjected to SDS-PAGE. The band containing the protein of interest was excised from the polyacrylamide gel and analyzed by mass spectrometry (this service was performed by Beijing Protein Institute, China).
1.7 Enzymatic action on M. lysodeikticus, X. c. malvacearum and $X$. o. oryzae cell walls

The enzymatic activity of $\mathrm{H} 5$ recombinant T4 lysozyme was compared with that of hen egg-white lysozyme using $M$. lysodeikticus (gram-positive) cell wall as the substrate. To prepare the substrate, a single M. lysodeikticus colony was selected from a $\mathrm{LB}\left(10 \mathrm{~g} \mathrm{~L}^{-1}\right.$ bacto-tryptone, $5 \mathrm{~g} \mathrm{~L}^{-1}$ yeast extract, $10 \mathrm{~g} \mathrm{~L}^{-1} \mathrm{NaCl}, 1.2 \%$ agar) plate and inoculated into 5 $\mathrm{mL}$ LB liquid medium in a $150 \mathrm{~mL}$ flask at $37^{\circ} \mathrm{C}$ with overnight vigorous shaking $\left(200 \mathrm{r} \mathrm{min}^{-1}\right)$. The cell pellet was collected by centrifugation at $5000 \times g$ for $5 \mathrm{~min}$ at room temperature, re-suspended in $500 \mathrm{~mL} 0.05 \mathrm{~mol} \mathrm{~L}^{-1}$ Tris- $\mathrm{HCl}(\mathrm{pH}$ 7.2) buffer, and separated again by centrifugation. The final cell pellet was re-suspended in the same buffer, frozen immediately at $-80^{\circ} \mathrm{C}$ for $30 \mathrm{~min}$, and freeze-dried (BYK Co., Ltd., Beijing, China) at $15 \mathrm{~Pa}$ and $-50^{\circ} \mathrm{C}$ for $30 \mathrm{~h} .100 \mathrm{mg}$ of freeze-dried M. lysodeikticus powder was suspended in 200 $\mathrm{mL}$ of $0.05 \mathrm{~mol} \mathrm{~L}^{-1}$ Tris-HCl, $\mathrm{pH} 7.2$ for use in the assay.

BSA (negative control; Roche), recombinant T4 lysozyme, and hen egg-white lysozyme solutions were diluted in 0.05 mol L ${ }^{-1}$ Tris- $\mathrm{HCl}(\mathrm{pH} 7.2)$ to concentrations of $0.0,1 \times 10^{-4}$, $5 \times 10^{-4}, 1 \times 10^{-3}, 5 \times 10^{-3}, 1 \times 10^{-2}, 5 \times 10^{-2}, 0.1,0.5$, and 1.0 $\mathrm{mg} \mathrm{mL} \mathrm{m}^{-1} .0 .1 \mathrm{~mL}$ of prepared lysozyme solution and $0.9 \mathrm{~mL}$ substrate $\left(0.5 \mathrm{~g} \mathrm{~L}^{-1}\right.$ M. lysodeikticus) were added to a $1.4 \mathrm{~mL}$ plastic cuvette, covered with Parafilm, gently inverted several times to mix, and incubated at $37^{\circ} \mathrm{C}$ for $1 \mathrm{~h}$. The turbidity change of the M. lysodeikticus suspension at $A_{350}$ measured with a spectrophotometer (Purkinje General Instrument Co. Ltd., Beijing, China) provided an estimate of lysozyme enzymatic activity. A decrease in the $350 \mathrm{~nm}$ absorbance $\left(A_{350}\right)$ of the mixture was caused by the lysis of M. lysodeikticus (1). X. c. malvacearum and X. o. oryzae cell wall lysis were measured by the same method.

\subsection{Lysozyme inhibition of bacteria}

A single M. lysodeikticus colony was selected from a LB plate and inoculated in $5 \mathrm{~mL}$ LB liquid medium in a $150 \mathrm{~mL}$ flask at $37^{\circ} \mathrm{C}$ with shaking $\left(200 \mathrm{r} \mathrm{min}^{-1}\right)$ overnight. The LB agar was boiled $\left(100^{\circ} \mathrm{C}\right)$ to melt, cooled to $45^{\circ} \mathrm{C}$, and maintained in a $45^{\circ} \mathrm{C}$ water bath. The M. lysodeikticus LB culture was diluted 1000 folds and $1 \mathrm{~mL}$ was transferred into $149 \mathrm{~mL} \mathrm{LB}$ agar in a $250 \mathrm{~mL}$ flask. After mixing the flask with vigorous shaking in the water bath, the inoculated agar was poured into a petri dish $(20 \mathrm{~mL})$. The plate was left undisturbed until the agar solidified. Three wells $(5 \mathrm{~mm}$ in diameter) from each plate were punched out with an aseptic hole punch. $50 \mu \mathrm{L} 10 \mathrm{mg} \mathrm{mL}^{-1}$ recombinant T4 lysozyme, BSA (negative control; Roche), and hen egg-white lysozyme (positive control) were pipetted into separate wells. After incubating the cultures at $37^{\circ} \mathrm{C}$ for $3 \mathrm{~d}$, zones of inhibition (diameters of the clear areas) were measured with a ruler $(\mathrm{mm})$. The diameter of the well was excluded. 
Growth inhibition for X. c. malvacearum and X. o. oryzae was assessed using the same method, except the culture medium for $X$. c. malvacearum was SOB $\left(20 \mathrm{~g} \mathrm{~L}^{-1}\right.$ bactotryptone, $5 \mathrm{~g} \mathrm{~L}^{-1}$ bacto-yeast extract, $\left.0.5 \mathrm{~g} \mathrm{~L}^{-1} \mathrm{NaCl}\right)$ and the culture medium for $X$. a. oryzae was PSA $\left(10 \mathrm{~g} \mathrm{~L}^{-1}\right.$ bacto-tryptone, $10 \mathrm{~g} \mathrm{~L}^{-1}$ sucrose, $1 \mathrm{~g} \mathrm{~L}^{-1} \mathrm{~L}$-glutamate).

\section{Results and discussion}

\subsection{Construction of recombinant vectors p9K-G-T4 and p9K-G-T4-rD}

Two yeast expression plasmids, p9K-G-T4 and p9K-G-T4$\mathrm{rD}$, were successfully constructed (Figure 1). The P. pastoris-derived pGAP promoter was used to drive T4 lysozyme expression in $H$. polymorpha in both plasmids. rDNA from $H$. polymorpha was introduced to p9K-G-T4-rD to test rDNA function on integrated homologous integration in $H$. polymorpha (16). Final DNA sequencing of the pGAP promoter, T4 lysozyme gene, and rDNA confirmed that they matched the GenBank database. The orientation of the cloned DNA fragments, and the structures of the intermediate vectors and the final expression constructs were verified by restriction endonuclease cleavage (data not shown).

\section{$2.2 H$. polymorpha A16 transformation}

rDNA is a site-specific integration element [16] and is the site of stable DNA integration in the yeast chromosome. We analyzed the transformation efficiency of the expression vector containing the 2.4-kb segment of $H$. polymorpha rDNA (partial 25S, a complete 5S, and the non-transcribed spacer region between $25 \mathrm{~S}$ and $18 \mathrm{~S}$ rDNA) [16]. p9K-G-T4 and p9K-G-T4-rD were linearized with $\mathrm{Xba}$ I and transformed into $H$. polymorpha A16 cells by electroporation. No transformants were obtained from plasmid p9K-G-T4. However, the transformation frequency of p9K-G-T4-rD was 100-1000 transformants/ $\mu$ g DNA. Ten of these transformants were randomly selected and screened using PCR analysis with T4 primer pairs; all contained the T4 lysozyme gene (data not shown). One hundred transformants were taken at random and screened on YPDS plates in the presence of different concentrations of G418. None of the transformants exhibited obvious growth inhibition when treated with $0.5 \mathrm{~g} \mathrm{~mL}^{-1} \mathrm{G} 418$, the transformants grew more slowly as the concentration of G418 was increased, and $70 \%$ transformants survived in the presence of $2 \mathrm{mg} \mathrm{mL}^{-1}$ G418 (data not shown). These results suggest that the transformants had multiple copies of the T4 lysozyme gene which allowed them to resist G418 selection pressure [13]. To estimate the copy-number of the T4 lysozyme gene in the transformants we selected a single colony, H5 from a $2 \mathrm{mg} \mathrm{mL}^{-1} \mathrm{G} 418$ plate. H5 genomic DNA was extracted, digested with $B g l$ II restriction enzyme, which did not cut within T4 lysozyme gene (cDNA), and subjected to Southern blot analysis. Two bands (11 and $9 \mathrm{~kb}$ ) were detected when blots were hybridized with the T4 lysozyme gene (495 bp) DNA probe (Figure 2).

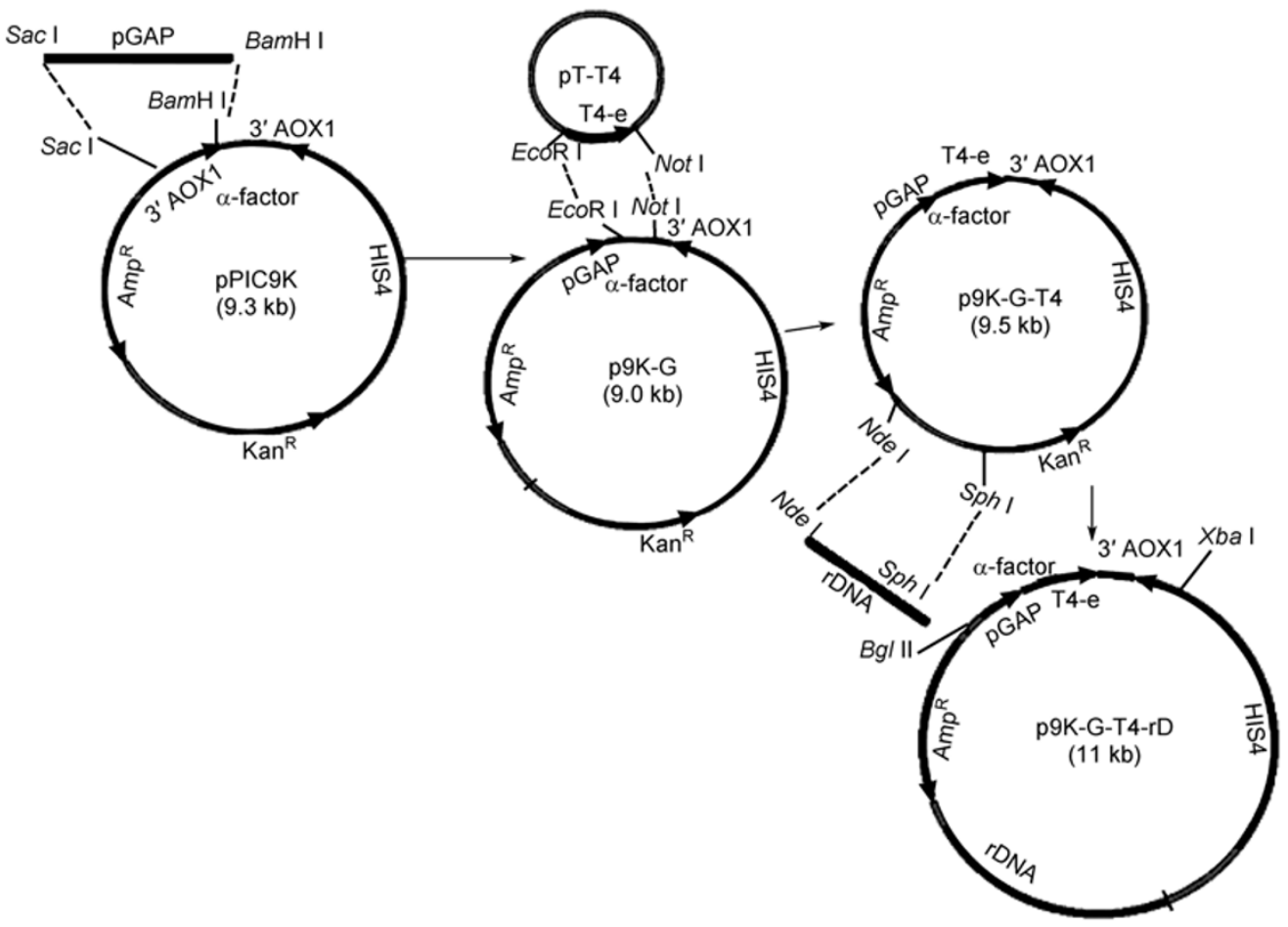

Figure 1 Construction of $H$. polymorpha T4-lysozyme expression system. pGAP, P. pastoris glyceraldehyde-3-phosphate dehydrogenase promoter; Amp ${ }^{\mathrm{R}}$, aminobenzylpenicillin-resistant gene; $\operatorname{Kan}^{\mathrm{R}}$, kanamycin-resistant gene; rDNA, ribosomal DNA. 


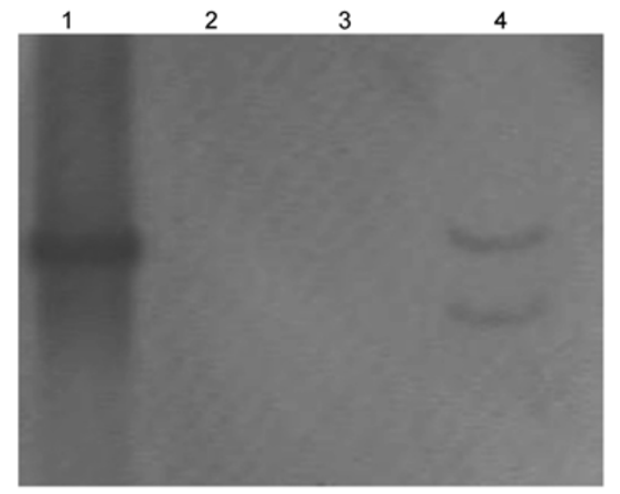

Figure 2 H5 transformant copy number was evaluated by Southern blot analysis. Lane 1, plasmid DNA p9k-G-T4-rD digested with Bglll (positive control); Lane 2, blank; Lane 3, H. polymorpha A16 genomic DNA (5 $\mu \mathrm{g})$; Lane 4, recombinant H5 genomic DNA $(5 \mu \mathrm{g})$.

Our results suggest that rDNA is required for DNA integration in $H$. polymorpha and is important for high-copynumber integration. These data are in accordance with other studies that show rDNA promotes efficient integration and transformation in $H$. polymorpha, and that 2-30 copies can be integrated into rDNA loci [17].

\subsection{Effects of $\mathrm{pH}$ and culture length on protein expres- sion}

To identify the optimal $\mathrm{pH}$ for growth of the transformants, $\mathrm{H} 5$ was inoculated into media at various $\mathrm{pH}$ values (Figure 3A).

Culture media were collected at 24,48 , and $72 \mathrm{~h}$ intervals. The growth of transformant yeast cultures was measured by absorbance at a wavelength of $660 \mathrm{~nm}\left(A_{660}\right)$. The $\mathrm{pH}$ of the culture media had a significant effect on the growth rate of the yeast. The optimal $\mathrm{pH}$ range for growth of $H$. polymorpha transformants was between 5.8 and 6.2, and growth rates successively declined as the $\mathrm{pH}$ of the media increased above 6.2. To identify the optimal time of harvest, recombinant T4 lysozyme expression was measured as a function of time. Recombinant T4 lysozyme protein was extracted from the cultures at different time points, treated with $0.2 \mathrm{~mol} \mathrm{~L}^{-1}$ DTT, and analyzed by SDS-PAGE (Figure 3B). The absorbance of cultures at $660 \mathrm{~nm}$ did not increase after $72 \mathrm{~h}$ incubation, which showed that the cells had reached confluence.

No expression of recombinant T4 lysozyme protein was observed at 24 and $48 \mathrm{~h}$ (data not shown). A $19 \mathrm{kD}$ protein band corresponding to T4 lysozyme protein $(18.7 \mathrm{kD})$ was observed in the $72 \mathrm{~h}$ culture. Based on these data, for subsequent experiments, we chose $\mathrm{pH} 6$ as optimal for the yeast growth medium and an incubation time of $72 \mathrm{~h}$ as an optimal harvest time.

\subsection{Production and characterization of recombinant T4 lysozyme}

Recombinant T4 lysozyme protein was expressed in $H$. po-
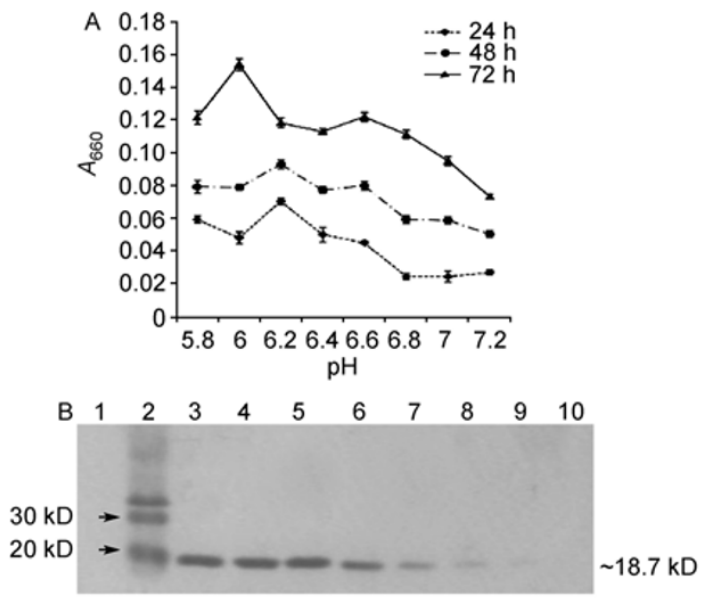

Figure 3 Specific growth rate of transformants at $37^{\circ} \mathrm{C}$ in media at various $\mathrm{pH}$ values (A) and SDS-PAGE analysis of recombinant T4 lysozyme proteins expressed in media at various $\mathrm{pH}$ values (B). A, The culture media were collected at 24,48 , and $72 \mathrm{~h}$. The growth rate was analyzed at $A_{660}$. Values are means of three replicates \pm SD. B, The cells were sampled at 72 $\mathrm{h}$ incubation. $10 \mu \mathrm{L}$ crude supernatant from each sample was loaded. Lane 1, H. polymorpha A16 supernatant (negative control); Lane 2, standard protein marker; Lanes 3-10, recombinant $\mathrm{H} 5$ supernatant sampled at $\mathrm{pH}$ $5.8,6.0,6.2,6.4,6.6,6.8,7.0,7.2$. Typical results from three similar experiments.

lymorpha and purified by dialysis. The N-terminal sequence of the SDS-PAGE band was analyzed by mass spectrometry and was identical to that of native T4 lysozyme (MNCFEMLR). When compared with various known concentrations of hen egg-white lysozyme, the yield of recombinant $\mathrm{T} 4$ lysozyme was $0.49 \mathrm{~g} \mathrm{~L}^{-1}$ culture medium. These observations confirm that foreign $\mathrm{T} 4$ lysozyme protein can be expressed in $H$. polymorpha under the control of the $P$. pastoris pGAP promoter. Our data are in accordance with previous reports which show that pGAP is useful for large-scale constitutive expression of many heterologous proteins in P.pastoris [18-20].

\subsection{Antimicrobial activity of recombinant T4 lysozyme}

The lytic activity of T4 lysozyme against the gram-positive bacteria $M$. lysodeikticus was determined by its enzymatic action on the cell wall [1]. A decrease in the absorbance of M. lysodeikticus cell wall suspensions (substrate solution) at $350 \mathrm{~nm}$ indicated an increase in recombinant T4 lysozyme concentration (Figure 4A).

The results show that recombinant $\mathrm{T} 4$ and hen egg-white lysozymes hydrolyzed the $M$. lysodeikticus cell wall, and indicate that recombinant T4 lysozyme possesses muramidase activity that can damage the peptidoglycan layers in bacterial cell walls [9]. However, the enzymatic activity of recombinant T4 lysozyme on the M. lysodeikticus cell wall was lower than that of hen egg-white. At $0.05 \mathrm{mg} \mathrm{mL}^{-1}$ protein, the $M$. lysodeikticus $A_{350}$ for hen egg-white and recombinant T4 lysozymes were 0.50 and 1.53 , respectively; at $1 \mathrm{mg} \mathrm{mL}{ }^{-1}$, the $A_{350}$ for recombinant T4 lysozyme was 


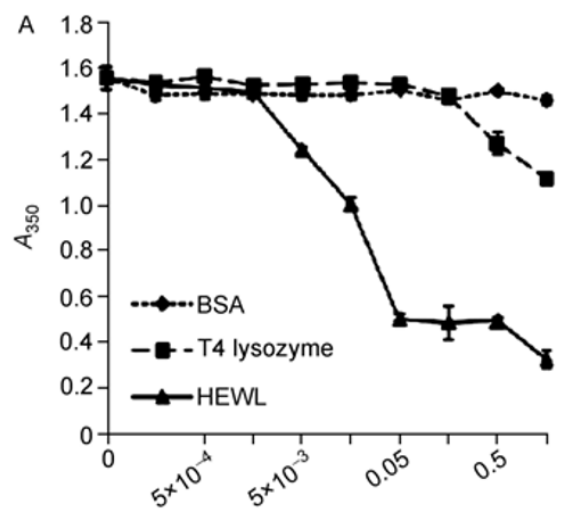

Protein concentration $\left(\mathrm{mg} \mathrm{mL}^{-1}\right)$

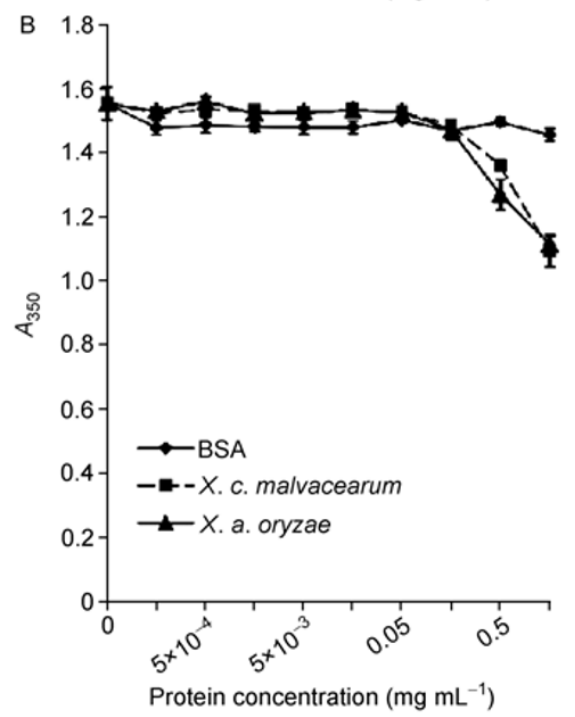

Figure 4 Hydrolysis of M. lysodeikticus cell wall by different concentrations of recombinant $\mathrm{T} 4$ phage lysozyme and hen egg-white lysozyme (HEWL; 0.0, $1 \times 10^{-4}, 5 \times 10^{-4}, 1 \times 10^{-3}, 5 \times 10^{-3}, 1 \times 10^{-2}, 5 \times 10^{-2}, 0.1,0.5,1.0$ $\left.\mathrm{mg} \mathrm{mL} \mathrm{m}^{-1}\right)(\mathrm{A})$ and hydrolysis of $X$. c. malvacearum and $X$. a. oryzae cell walls by different concentrations of recombinant $\mathrm{T} 4$ phage lysozyme $(0.0$, $\left.1 \times 10^{-4}, 5 \times 10^{-4}, 1 \times 10^{-3}, 5 \times 10^{-3}, 1 \times 10^{-2}, 5 \times 10^{-2}, 0.1,0.5,1.0 \mathrm{mg} \mathrm{mL}^{-1}\right)(\mathrm{B})$. A, BSA was the negative control. Cell turbidity was determined spectrophotometrically at $A_{350}$. Values are means of three replicates \pm SD. B, BSA was the negative control. The cell turbidity was determined spectrophotometrically at $A_{350}$. Values are means of three replicates \pm SD

1.11. In contrast to these data, previous reports showed that phage T4 lysozyme had higher lytic activity than that of hen egg-white [1]. We found that recombinant T4 lysozyme also lysed the gram negative bacteria, X. c. malvacearum and $X$. a. oryzae. Based on these results, we propose that recombinant T4 lysozyme disrupts or alters the outer membrane layers of gram negative bacteria and causes them to form osmotically fragile rods [21].

The antimicrobial activity of recombinant T4 lysozyme was confirmed by measuring zones of inhibition on bacterial culture agar plates. As shown in Table 1, recombinant T4 lysozyme inhibited the growth of $X$. c. malvacearum and $X$. a. oryzae with inhibition zone diameters of $(11 \pm 1)$ and $(19.3 \pm 0.58) \mathrm{mm}$, respectively. However, recombinant T4 lysozyme did not inhibit $M$. lysodeikticus growth even though it exhibited the ability to lyse the cell wall. In addition, the inhibition assay indicated that recombinant T4 lysozyme has lower antibacterial ability than hen egg-white (M. lysodeikticus, $(34.7 \pm 0.58) \mathrm{mm} ; X$. c. malvacearum, $(35 \pm 1) \mathrm{mm} ; X$. a. oryzae, $(21 \pm 1) \mathrm{mm})$. We also used E. coli (gram-negative) to measure recombinant T4 lysozyme bactericidal activity. Our results show that recombinant T4 and hen egg-white lysozymes had no effects on the growth of $E$. coli (Table 1). These data are in contrast to reports showing native T4 lysozyme degradation of the periplasmic peptidoglycan layer of E. coli (9).

Disulfide bond formation of recombinant T4 lysozyme was analyzed by DTT treatment. DTT is commonly used to reduce disulfide bonds in proteins [22]. Concentrated recombinant T4 lysozyme was treated with or without DTT and analyzed by SDS-PAGE (Figure 5). In the presence of DTT (Figure 5, Lane 2), a single band was produced with a molecular weight of $18.7 \mathrm{kD}$, which is equivalent to the molecular weight of native T4 lysozyme. Two bands were observed without DTT treatment (Figure 5, Lane 1). The major band in the untreated sample was approximately 15 $\mathrm{kD}$. A minor band had a molecular weight of $31 \mathrm{kD}$. These data indicate that most recombinant T4 lysozyme forms intramolecular disulfide bonds, and some forms intermolecular disulfide bonds.

We also overexpressed T4 lysozyme in E. coli. However, after T4 transformation, the yield was very low as most of

Table 1 Zones of inhibition $(\mathrm{mm})^{\mathrm{a})}$

\begin{tabular}{ccc}
\hline & T4 lysozyme & HEWL \\
\hline E. coli & 0 & 0 \\
M. lysodeikticus & 0 & $34.7 \pm 0.58$ \\
X. c. malvacearum & $11 \pm 1$ & $35 \pm 1$ \\
X. a. oryzae & $19.3 \pm 0.58$ & $21 \pm 1$ \\
\hline
\end{tabular}

a) Comparison of the bactericidal activities of recombinant $\mathrm{T} 4$ phage lysozyme and hen egg-white lysozyme (HEWL) based on the average diameter $(\mathrm{mm})$ of the zones of inhibition. $10 \mathrm{mg} \mathrm{mL}^{-1}$ protein was used for the assay. Values are means of three replicates \pm SD.

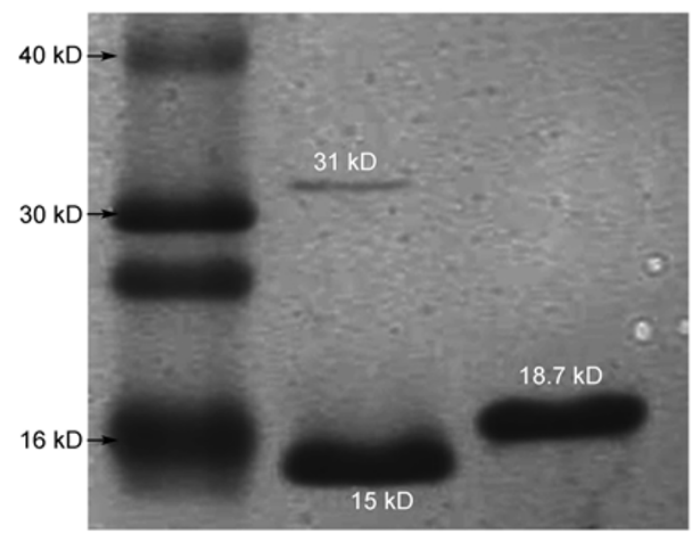

Figure 5 SDS-PAGE analysis of T4 disulfide bonds. Lane 1, standard protein weight; Lane 2, T4 lysozyme supernatant without DTT treatment; Lane 3, T4 lysozyme supernatant with DTT treatment. 
the E. coli was hydrolyzed (data not shown). Functional native T4 lysozyme has two cysteines, but it does not form disulfide bonds [8,22]. By contrast, recombinant T4 lysozyme produced from $H$. polymorpha was unable to degrade the peptidoglycan in E. coli probably because it possessed incorrectly formed disulfide bonds which affected protein activity [23]. Future studies may involve altering one of the T4 phage lysozyme cysteines to prevent the formation of these disulfide bonds.

\section{Conclusion}

The $H$. polymorpha system has been widely used for heterologous protein production. In this study, we used the $H$. polymorpha expression system to produce T4 phage lysozyme. The protein was driven by the $P$. pastoris pGAP promoter. We produced a large quantity of recombinant T4 lysozyme $\left(0.49 \mathrm{~g} \mathrm{~L}^{-1}\right.$ culture broth supernatant) in a relatively short period of time $(72 \mathrm{~h})$, as compared with the $E$. coli protein expression system. The $H$. polymorpha-derived rDNA-targeting element was found to be essential for overexpressing recombinant $\mathrm{T} 4$ lysozyme in $H$. polymorpha. Without the rDNA-targeting element, the foreign T4 lysozyme could not be integrated into the $H$. polymorpha genome. Recombinant T4 lysozyme inhibited certain species of gram positive and gram negative bacteria. However, it exhibited lower enzyme activity than hen egg-white lysozyme. Investigations of the protein structure of recombinant T4 lysozyme indicated that it formed disulfide bonds which resulted in the loss of lysozyme activity. Further experiments are needed to develop strategies to prevent erroneous disulfide bond formation in recombinant $\mathrm{T} 4$ lysozyme in the $H$. polymorpha expression system.

This work was supported by the National High Technology Research \& Development Program of China (Grant No. 2007AA02Z111), National Technology for the 10th Five-year Plan of China (Grant No. 2006BAD31B01-04), National Biotechnology Development Plan (Grant Nos. 2008ZX08005-004 and 2009ZX08005-004B), and the Researcher Foundation of the Chinese Academy of Agricultural Sciences. The authors thank Drs. Leslie Fuchigami (Oregon State University, OR, USA) and Donna Balding (Macon State College, GA, USA) for reviewing and editing the manuscript.

1 Tsugita A, Inouye M. Purification of bacteriophage T4 lysozyme. J Biol Chem, 1968, 243: 391-397

2 Wang S Y, Ng T B, Chen T B, et al. First report of a novel plant lysozyme with both antifungal and antibacterial activities. Biochem Biophys Res Commun, 2005, 327: 820-827

3 Merlini G, Bellotti V. Lysozyme: A paradigmatic molecule for the investigation of protein structure, function and misfolding. Clin Chim Acta, 2005, 357: 168-172
4 Schulenburg H, Boehnisch C. Diversification and adaptive sequence evolution of Caenorhabditis lysozymes (Nematoda: Rhabditidae). BMC Evolutionary Biology (online), 2008, 8: 114, http://www.biomedcentral. com/1471-2148/8/114. ISSN 1471-2148

5 Liu S T, Saito A, Azakami H, et al. Expression, purification, and characterization of an unstable lysozyme mutant in Pichia pastoris. Protein Expr Purif, 2003, 27: 304-312

6 Masuda T, Ueno Y, Kitabatake N. High yield secretion of the sweet-tasting protein lysozyme from the yeast Pichia pastoris. Protein Expr Purif, 2005, 39: 35-42

7 Ye J L, Wang C B, Chen X H, et al. Marine lysozyme from a marine bacterium that inhibits angiogenesis and tumor growth. Appl Microbiol Biotechnol, 2008, 77: 1261-1267

8 Matthews B W. Structural and genetic analysis of the folding and function of T4 lysozyme. FASEB J, 1996, 10: 35-41

9 Hu D H, Lu P H. Placing single-molecule T4 lysozyme enzymes on a bacterial cell surface: Toward probing single-molecule enzymatic reaction in living cells. Biophys J, 2004, 87: 656-661

10 Dong S J, Shew D H, Tredway L P, et al. Expression of the bacteriophage T4 lysozyme gene in tall fescue confers resistance to gray leaf spot and brown patch diseases. Transgenic Res, 2008, 17: 47-57

11 Perry J L, Heyneker H L, Wetzel R. Non-toxic expression in Escherichia coli of a plasmid-encoded gene for phage T4 lysozyme. Gene, 1985, 38: 259-264

12 Heo J H, Won H S, Kang H A, et al. Purification of recombinant human epidermal growth factor secreted from the methylotrophic yeast Hansenula polymorpha. Protein Expr Purif, 2002, 24: 117-122

13 Wu J X, Fu W Z, Luo J X, et al. Tianyuan. Expression and purification of human endostatin from Hansenula polymorpha A16. Protein Expr Purif, 2005, 42: 12-19

14 Qian W D, Liu Y Y, Zhang C Z, et al. Expression of bovine follicle-stimulating hormone subunits in a Hansenula polymorpha expression system increases the secretion and bioactivity in vivo. Protein Expr Purif, 2009, 68: 183-189

15 Gellissen G, Kunze G, Gaillardin C, et al. New yeast expression platforms based on methylotrophic Hansenula polymorpha and Pichia pastoris and on dimorphic Arxula adeninivorans and Yarrowia lipolytica-a comparison. FEMS Yeast Res, 2006, 5: 1079-1096

16 Klabunde J, Diesel A, Waschk D, et al. Single-step co-integration of multiple expressible heterologous genes into the ribosomal DNA of the methylotrophic yeast Hansenula polymorpha. Appl Microbiol Biotechnol, 2002, 58: 797-805

17 Liu Y Y, Li Y, Liu L Y, et al. Design of vectors for efficient integration and transformation in Hansenula polymorpha. Biotechnol Lett, 2005, 27: 1529-1534

18 Aloulou A, Grandval P, De Caro J, et al. Constitutive expression of human pancreatic lipase-related protein 1 in Pichia pastoris. Protein Expr Purif, 2006, 47: 415-421

19 Chen G H, Yin L J, Chiang H, et al. Expression and purification of goat lactoferrin from Pichia pastoris expression system. J Food Sci, 2007, 72: 67-71

20 Qiao J Y, Rao Z H, Dong B, et al. Expression of Bacillus subtilis MA139 $\beta$-mannanase in Pichia pastoris and the enzyme characterization. Appl Biochem Biotechnol, 2010, 160: 1362-1370

21 Benkerroum N. Antimicrobial activity of lysozyme with special relevance to milk. Afr J Biotechnol, 2008, 7: 4856-4867

22 Van De Guchte M, Van Der Wal F J, Kok J, et al. Lysozyme expression in Lactococcus lactis. Appl Microbiol Biotechnol, 1992, 37: 216-224

23 Chim N, Riley R, The J, et al. An extracellular disulfide bond forming protein (DsbF) from Mycobacterium tuberculosis: Structural, biochemical, and gene expression analysis. J Mol Biol, 2010, 396: 1211-1226

Open Access This article is distributed under the terms of the Creative Commons Attribution License which permits any use, distribution, and reproduction in any medium, provided the original author(s) and source are credited. 